九州大学学術情報リポジトリ

Kyushu University Institutional Repository

Relationship between the Discharge Rate and the Maximum Hydrostatic Pressure upon Wet-Grinding of Soybean Using a Double-Disk Attrition Mill

Furuta, Shu

Laboratory of Food Processing, Faculty of Agriculture, Kyushu University

Hayakawa, Isao

Laboratory of Food Processing, Faculty of Agriculture, Kyushu University

Fujio, Yusaku

Laboratory of Food Processing, Faculty of Agriculture, Kyushu University

https://doi.org/10.5109/23951

出版情報 : 九州大学大学院農学研究院紀要. 35 (1/2)，pp.65-71，1990-12. Kyushu University バージョン：

権利関係 : 


\title{
Relationship between the Discharge Rate and the Maximum Hydrostatic Pressure upon Wet-Grinding of Soybean Using a Double-Disk Attrition Mill
}

\author{
Shu Furuta, Isao Hayakawa and Yusaku Fujio \\ Laboratory of Food Processing, Faculty of Agriculture, \\ Kyushu University 46-09, Fukuoka 812 \\ (Received July 23, 1990)
}

\begin{abstract}
Wet-grinding of soybean was done in order to investigate the relationship between the discharge rate of soybean slurry from the disk gap and the maximum hydrostatic pressure exerted on the disk gap by a modified double-disk attrition mill. The discharge rate was estimated from the disk rotational speed, disk gap width, and soybean cincentration. The discharge rate, mainly dependent on the disk gap width, decreased with the narrowing of the disk gap width (from 0.254 to $0.115 \mathrm{~mm}$ ). On the other hand, the maximum hydrostatic pressure exerted was inversely proportional to the disk gap width.
\end{abstract}

\section{INTRODUCTION}

Wet-grinding has been reported as a more effective process for size reduction of coal (Celik, 1988 ;Ito et al., 1988 ; Koka and Trass, 1985a; Koka et al., 1985b), dyestuff (Heim and Leszczyniecki, 1985), Si powder (Suzuki and Kuwahara, 1986), and sodalime-silica mixture (Kanda et al., 1988), The effectiveness of wet-grinding could be increased with the reduction of particle surface energy, depression of particle aggregation, and homogeneous dispersion of particles. In food processing industry in Japan, the wet-grinding processes have been applied to productions of soybean curd, sesamesoybean curd, protein extraction, starch manufacturing, etc. There are, however, few fundamental research works for food materials except the ingredients separation (Fujio and Furuta, 1989 ; Furuta et al., 1989) by the wet-grinding process.

In this paper, we demonstrated the relationship between the discharge rate from the disk gap and the maximum hydrostatic pressure exerted on the disk gap.

\section{MATERIALS AND METHODS}

\section{Soybean}

Dehulled soybean (product of North America, 1989), used in this experiment, was pre-crushed to particle size under $1 \mathrm{~mm}$ in diameter with an attrition mill (Jiyu Funsaiki M-2, Nara Kikai Co. Ltd., Tokyo, Japan).

\section{Attrition mill}

A commercial single-runner disk attrition mill (NSG-08, Nagasawa Kikai Co. Ltd., Saitama, Japan) was used for the wet-grinding operation. It was mounted on a stationary disk of 80 mesh emery and a runner disk (Noritake Diamond Tools Co., 
Nagoya, Japan) covered with sharp edged diamond particles of 120 mesh. The disk gap width between the stationary and the runner disk was adjustable and measured by a standard thickness gauge. The rotational speed of the runner disk was regulated ranging from 960 to $1,860 \mathrm{rpm}$. Five pressure taps were mounted within the radial direction of the stationary disk (Fig. 1-2). Hydrostatic pressures exerted by wetgrinding were measured with bourden gauges (Pressure Gauge AS 3/8, Kusaba Gauge MFG. Co. Ltd., Osaka, Japan ; Compound Gauge BU 3/8, Daito Keiki Seisakusho Ltd., Hiroshima, Japan).

\section{Wet-grinding}

Pre-crushed soybean was suspended in deionized water, and its concentration was adjusted to $10, \mathbf{1 5}, \mathbf{2 0}$, and $\mathbf{2 5 \%}(\mathbf{w} / \mathbf{w})$. The soybean slurry was introduced at (a), then passed through the disk gap and discharged from the periphery of disk (b) into the stationary casing of the mill (Fig. 1-1). During the wet-grinding operation, a feed level of soybean slurry was maintained at constant height to keep a certain pressure head and prevent an air inflow. The hydrostatic pressures at five pressure taps (Fig. 1-2), disk rotational speed, and discharge rate from the disk gap were measured during the wet-grinding operation. Maximum hydrostatic pressure was established as the highest hydrostatic pressure (at Pressure Tap of $\mathrm{T}_{3}, \mathrm{~T}_{4}$, and $\mathrm{T}$,) exerted on the disk gap. Centrifugal force on the soybean slurry was calculated from the logarithmic mean of disk radii of Pressure Tap of $T_{3}\left(r_{1}\right)$ and $T_{5}\left(r_{2}\right)$ (Fig. 1-2), discharge rate of soybean

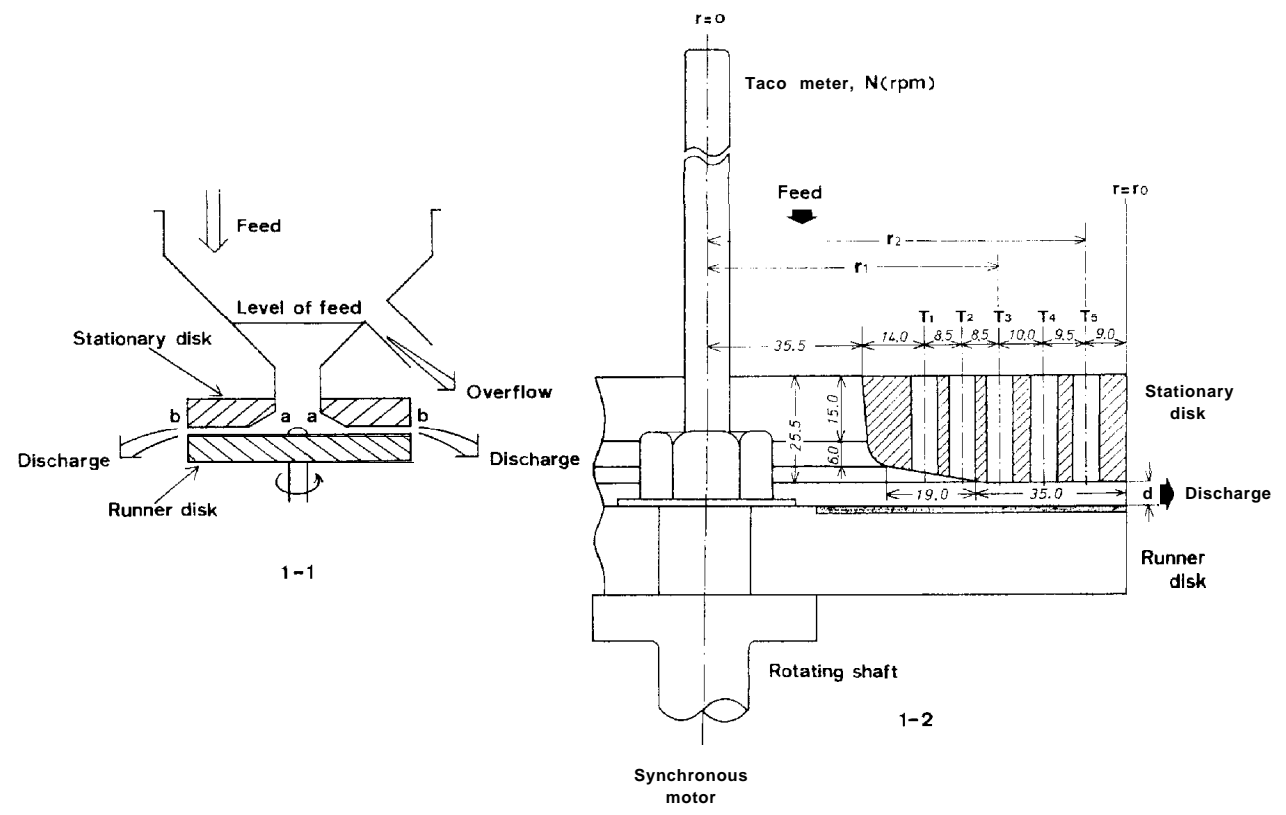

Figure 1. Grinding mechanism of double-disk attrition mill(1-1) and position of pressure tap on stationary disk (1-2). a, inlet zone ; b, outlet zone. 


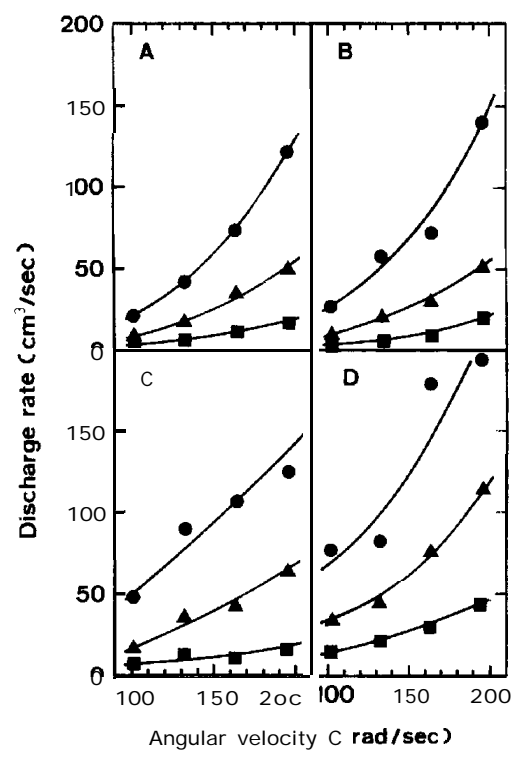

Figure 2. Relationship between disk rotational speed (in angular velocity) and discharge rate of soybean slurry. A, $25 \%(\mathrm{w} / \mathrm{w})$ soybean concentration ; B, $20 \%(\mathrm{w} / \mathrm{w})$ soybean concentration $; \mathrm{C}, 15 \%(\mathrm{w} / \mathrm{w})$ soybean concentration $; \mathrm{D}, 10 \%(\mathrm{w} / \mathrm{w})$ soybean concentration. $0.254 \mathrm{~mm}$ disk gap width ; A, $0.185 \mathrm{~mm}$ disk gap width ; $\quad 0.115$ mm disk gap width.

slurry, density of soybean slurry, and rotational speed of runner disk.

\section{RESULTS AND DISCUSSION}

\section{E ffect of disk rotational speed on the discharge rate}

Figure 2 shows the relationship between the disk rotational speed (in angular velocity) and the discharge rate of soybean slurry. The discharge rate increased with both the widening of the disk gap width (from 0.115 to $0.254 \mathrm{~mm}$ ) and the decrease in soybean concentration (from 25 to $10 \%(\mathrm{w} / \mathrm{w})$ ). There were, however, few effects of the soybean concentration (at 15, 20, and 25\% (w/w)) at the disk gap widths of 0.115 and $0.185 \mathrm{~mm}$. Hence, for soybean slurry grinding by the double-disk attrition mill, it was proved that the discharge rate of soybean slurry could be determined by the combination of the disk rotational speed, disk gap width, and soybean concentration ; with the discharge rate being mainly dependent on the disk rotational speed.

\section{Centrifugal force occurring in the disk gap}

As shown in Fig. 3, the relationship between the centrifugal force (acting on an average discharge volume of soybean slurry per second) and the disk rotational speed (in angular velocity) was replotted on a semilogarithmic scale from the previous data (Fig. 2). The centrifugal force increased when the disk gap widened from 0.115 to $0.254 \mathrm{~mm}$ and soybean concentration decreased from 25 to $10 \%$ (w/w). Reversely, 


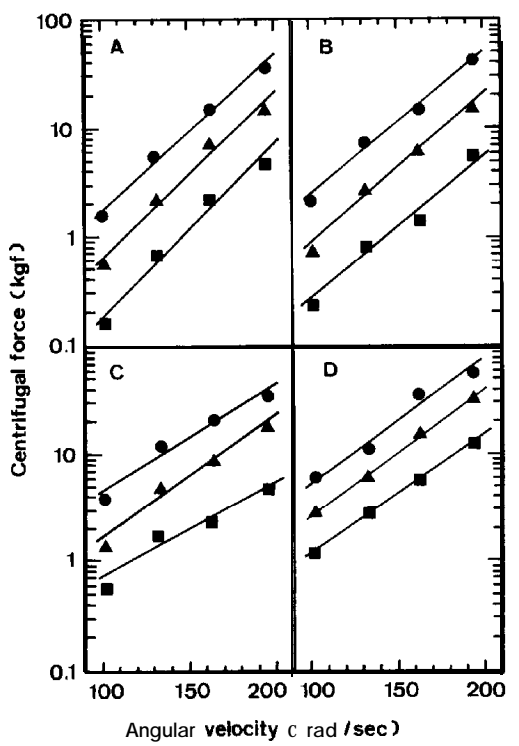

Figure 3. Relationship between centrifugal force acting on average discharge volume of soybean slurry per second and disk rotational speed (in angular velocity). A, 25\% $(\mathrm{w} / \mathrm{w})$ soybean concentration ; B, 20\% (w/w) soybean concentration ; C, 15\% (w/w) soybean concentration; D, $10 \%(\mathrm{w} / \mathrm{w})$ soybean concentration. $0.254 \mathrm{~mm}$ disk gap width ; $\boldsymbol{\Delta}, 0.185 \mathrm{~mm}$ disk gap width; $\mathbf{\square}, 0.115 \mathrm{~mm}$ disk gap width.

the centrifugal force acting in the disk gap could be lowered with increasing of the moving resistance of soybean slurry by both the narrowing of the disk gap width and the increase of the soybean concentration. Considering from the view point of the size reduction of soybean particles, the centrifugal force acting in the disk gap seemed to act as a projectile force of flow, which discharges the soybean slurry out from the disk gap, rather than the attrition force that promoted the size reduction of soybean particles.

\section{Effect of disk gap on the discharge rate}

Figure 4 shows the relationship between the centrifugal force (calculated in Fig. 3) and the discharge rate of soybean slurry. A decrease of the centrifugal force resulted to the decrease of the discharge rate, regardless of both the soybean concentration and the disk gap width. However, the discharge rate in the disk gap width of $0.115 \mathrm{~mm}$ was extremely smaller than those in the other disk gap widths (of 0.185 and 0.254 $\mathrm{mm}$ ). Clearly, the discharge rate was markedly dependent on the disk gap width rather than the centrifugal force. The narrowing of the disk gap width thus seemed to function as a rate-limiting step to the discharge rate of soybean slurry.

Relationship between the maximum hydrostatic pressure and the discharge rate Figure 5 shows the relationship between the maximum hydrostatic pressure (at 


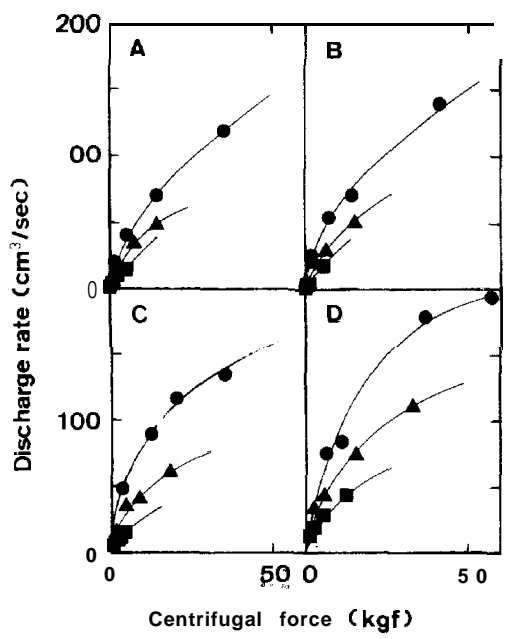

Figure 4. Relationship between centrifugal force acting on average discharge volume of soybean slurry per second and discharge rate of soybean slurry. A, $25 \%(\mathrm{w} / \mathrm{w})$ soybean concentration ; B, 20\% $(\mathrm{w} / \mathrm{w})$ soybean concentration ; C, $15 \%(\mathrm{w} / \mathrm{w})$ soybean concentration; D, $10 \%(\mathrm{w} / \mathrm{w})$ soybean concentration. $0.254 \mathrm{~mm}$ disk gap width $; \boldsymbol{\Lambda}$, $0.185 \mathrm{~mm}$ disk gap width; $\mathbf{\square}, 0.115 \mathrm{~mm}$ disk gap width.

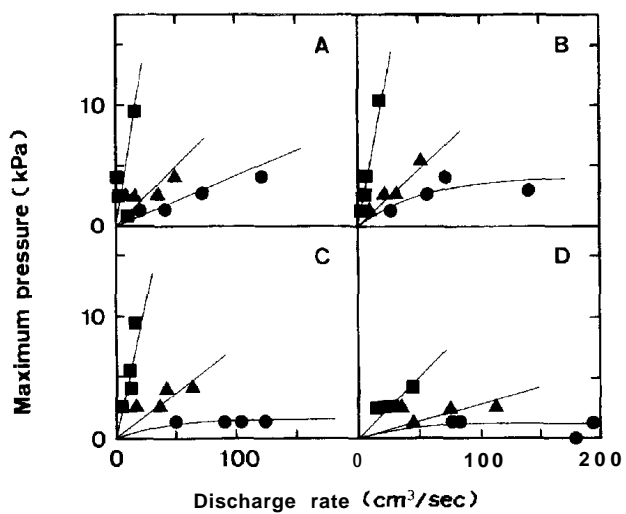

Figure 5. Relationship between maximum pressure (at Pressure Tap of $T_{,}, T_{4}$, and $T_{5}$ ) exerted on disk gap and discharge rate from disk gap. A, 25\% (w/w) soybean concentration; B, 20\% (w/w) soybean concentration; C, $15 \%(\mathrm{w} / \mathrm{w})$ soybean concentration ; D, $10 \%(\mathrm{w} / \mathrm{w})$ soybean concentration. $0.254 \mathrm{~mm}$ disk gap width; $\mathbf{\Lambda}, 0.185 \mathrm{~mm}$ disk gap width ; $0.115 \mathrm{~mm}$ disk gap width.

Pressure Tap of $T_{3}, T_{4}$, and $T$,) exerted on the disk gap and the corresponding discharge rate. The discharge rate of soybean slurry decreased with the narrowing of the disk gap width (from 0.254 to $0.115 \mathrm{~mm}$ ), but the maximum hydrostatic pressure exerted on the disk gap conversely increased with the narrowing of the disk gap width. This indicates that the soybean slurry discharged from the disk gap, as shown in Fig. 


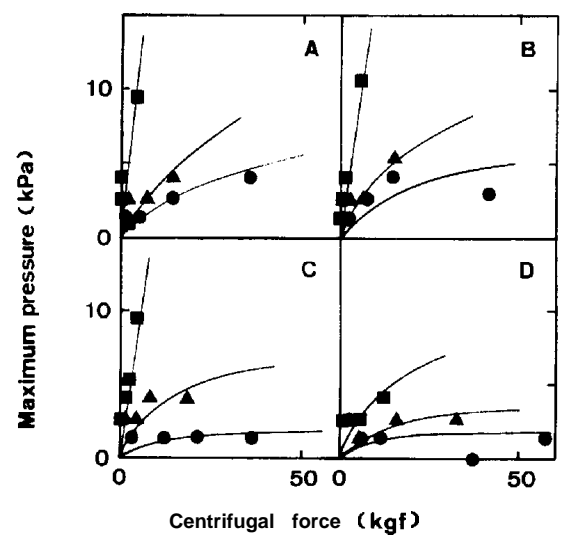

Figure 6. Relationship between maximum pressure (at Pressure Tap of $T_{3}, T_{4}$, and $T_{5}$ ) exerted on disk gap and centrifugal force acting on average discharge volume of soybean slurry per second. A, 25\% (w/w) soybean concentration ; B, 20\% $(\mathrm{w} / \mathrm{w})$ soybean concentration ; C, 15\% (w/w) soybean concentration ; D, 10\% (w/w) soybean concentration, $0.254 \mathrm{~mm}$ disk gap width $; \boldsymbol{\Delta}, 0.185 \mathrm{~mm}$ disk gap width ; $\quad, 0.115 \mathrm{~mm}$ disk gap width.

3, was guided by a projectile force of flow by disk rotation, but the flow of soybean slurry could be prescribed by the disk gap width. Accordingly, a decrease of the flow of soybean slurry on the basis of the narrowing of the disk gap width (from 0.254 to $0.115 \mathrm{~mm}$ ) could appear as an increase of the maximum hydrostatic pressure exerted on the disk gap.

\section{Relationship between the maximum hydrostatic pressure and the centrifugal force}

Figure 6 shows the relationship between the maximum hydrostatic pressure (at Pressure Tap of $T_{3}, T_{4}$, and $T_{5}$ ) exerted on the disk gap and the calculated centrifugal force. The narrowing of the disk gap width (from 0.254 to $0.115 \mathrm{~mm}$ ) resulted to a decrease of the centrifugal force, but the maximum hydrostatic pressure exerted, increased with the narrowing of the disk gap width. In the disk gap (of Pressure Tap of $\mathrm{T}_{3}, \mathrm{~T}_{4}$, and $\mathrm{T}$,), a force which was different from the centrifugal force (as a projectile force on the flow of soybean slurry) seemed to act as the attrition force which promoted the size reduction of soybean particles, and such force was enhanced by narrowing the disk gap width. At disk gap widths of $0.254 \mathrm{~mm}$ (soybean concentration of 10 and $15 \%(\mathrm{w} / \mathrm{w})$ ) and $0.185 \mathrm{~mm}$ (Soybean concentration of $10 \%(\mathrm{w} / \mathrm{w})$ ), the maximum hydrostatic pressures were at relatively constant values in spite of the changes in the centrifugal force owing to changes in both the disk rotational speed and the discharge rate of soybean slurry. The flow of soybean slurry appeared to be more prevalent rather than the size reduction of soybean particles at a disk gap width above $0.185 \mathrm{~mm}$ and in a soybean concentration under $15 \%(\mathrm{w} / \mathrm{w})$.

Consequently, in the case of wet-grinding with a double-disk attrition mill, it could be suggested that Bernoulli's equation applies to the relationship between the discharge rate of soybean slurry from the disk gap and the maximum hydrostatic pressure 
exerted on the disk gap. Therefore, we presumed that the size reduction of soybean particles could be affected more by the attrition force acting upon grinding of soybean particles rather than that of the centrifugal force acting to discharge the soybean slurry from the disk gap.

\section{REFERENCES}

Celik, M. S. 1988 A comparison of dry and wet fine grinding of coals in a ball mill. Powder Technol., $55: 1-9$

Fujio, Y. and S. Furuta 1989 Fractionation of water insoluble solids and extraction of pectins from residues of juice-extracted satsuma mandarin fruit by wet grinding. Int. J.Food Sci. Technol., $24: 439-445$

Furuta, S., I. Hayakawa and Y. Fujio 1989 Classification of the constituents of citrus juice residue by a wet-grinding process. J. Fuc. Agr., Kyushu Univ., $34: 101-106$

Heim, A. and R. Leszczyniecki 1985 Determination of parameters for wet-grinding model in perl mills. Powder Technol., 41 : 173-179

Ito, H., S. Tatsumi, Y. Kajibata and S. Takao 1988 Characteristics of wet grinding of highly concentrated coal water slurry. Kagaku Kogaku Ronbunshu, 14(2):155-160 (in Japanese with English summary)

Kanda, Y., Y. Abe, M. Yamaguchi and C. Endo 1988 A fundamental study of dry and wet grinding from the viewpoint of breaking strength. Powder Technol., 56:57-62

Koka, V. R. and 0. Trass 1985a Analysis of the kinetics of coal breakage by wet grinding in the szego mill. Powder Technol., 43 : 287-294

Koka, V. R., G. Papachristodoulou and 0. Trass 1985b Settling stability of coal slurries prepared by wet grinding in the szego mill. Can. J.Chem. Eng., $63: 585^{-590}$

Suzuki, K. and Y. Kuwahara 1986 Effects of fluids on vibration ball mill grinding. J. Chem. Eng. Jpn., 19(3): 191-195 